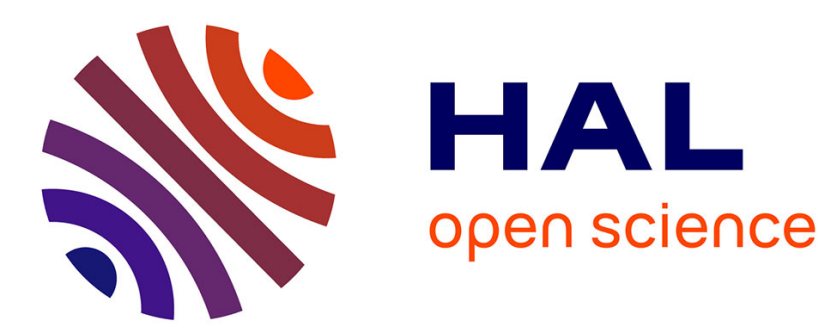

\title{
Timing and rate of sexual maturation of European eel in brackish and freshwater environments
}

Danièle Bevacqua, Paco Melià, Alain Jean Crivelli, Giulio Alessandro de Leo, Marino Gatto

\section{- To cite this version:}

Danièle Bevacqua, Paco Melià, Alain Jean Crivelli, Giulio Alessandro de Leo, Marino Gatto. Timing and rate of sexual maturation of European eel in brackish and freshwater environments. Journal of Fish Biology, 2006, 69, pp.200-208. 10.1111/j.1095-8649.2006.01265.x . hal-02658860

\section{HAL Id: hal-02658860 https://hal.inrae.fr/hal-02658860}

Submitted on 30 May 2020

HAL is a multi-disciplinary open access archive for the deposit and dissemination of scientific research documents, whether they are published or not. The documents may come from teaching and research institutions in France or abroad, or from public or private research centers.
L'archive ouverte pluridisciplinaire HAL, est destinée au dépôt et à la diffusion de documents scientifiques de niveau recherche, publiés ou non, émanant des établissements d'enseignement et de recherche français ou étrangers, des laboratoires publics ou privés. 


\title{
BRIEF COMMUNICATIONS
}

\section{Timing and rate of sexual maturation of European eel in brackish and freshwater environments}

\author{
D. Bevacqua*†, P. Meliàt, A. J. Crivelli§, G. A. De Leo* \\ AND M. GatTo: \\ *Dipartimento di Scienze Ambientali, Università degli Studi di Parma, Viale G.P. Usberti \\ 11/A, I-43100 Parma, Italy, \$Dipartimento di Elettronica e Informazione, Politecnico di \\ Milano, via Ponzio 34/5, I-20133 Milano, Italy and §Station Biologique de la Tour du \\ Valat, Le Sambuc, F-13200 Arles, France
}

\begin{abstract}
Maturation rates in three European eel Anguilla anguilla populations increased from September to October and were slightly lower in fresh water than in brackish waters. Average and variance of total length at maturation were larger in females than males.

(C) 2006 The Authors

Journal compilation (C) 2006 The Fisheries Society of the British Isles
\end{abstract}

Key words: Anguilla anguilla; European eel; maturation curves; sexual maturation; silvering rates.

The European eel Anguilla anguilla (L.) is a catadromous fish: individuals grow and feed in brackish and fresh waters as yellow eels until sexual maturation, when they metamorphose to the silver stage and leave continental waters to reach their spawning grounds in the Sargasso Sea. Sexual maturation of European eels, as well as sex differentiation, depend upon body size rather than age, with fastgrowing individuals maturing earlier than slower ones (Vøllestad \& Jonsson, 1988; De Leo \& Gatto, 1995). Sex differentiation and maturation, along with the differences in the growth paths of males and females, play a key role in determining the size and sex structure of $A$. anguilla populations. European eels show indeed delayed sex differentiation and clear sexual dimorphism, with females attaining larger body size and starting sexual maturation later than males (Vøllestad, 1992; Krueger \& Oliveira, 1999). Accordingly, the population size structure of the spawning stock is clearly bimodal. The differences in maturation between males and females affect the timing of migration, alter the sex ratio and influence the effective output of spawners of European eel populations. Identifying the triggers for metamorphosis and understanding the way environmental factors affect sex maturation of European eels is one of the preliminary steps needed to develop reliable demographic models which, in turn, can provide

†Author to whom correspondence should be addressed. Tel.: +39 0521905 619; fax: + 390521905 402; email: bevacqua@dsa.unipr.it 
effective tools for the management and conservation of this charismatic, yet endangered fish species.

Metamorphosis processes have been deeply debated in the last years (Beullens et al., 1997; Svedäng \& Wickström, 1997; Durif et al., 2005). Most studies have been aimed at describing the morphological and physiological changes occurring during metamorphosis, but only very few of them have been oriented to the estimation of maturation rates by calibrating mathematical models on available data (De Leo \& Gatto, 1995, 1996). In fact, although modelling approaches have already been used to describe different aspects of the complex life cycle of A. anguilla, such as natural recruitment (Lambert, 1994; Dekker, 2000a, 2003), body growth (De Leo \& Gatto, 1995; Poole \& Reynolds, 1996; Melià et al., 2006a), and fishing mortality (Moriarty \& Dekker, 1997; Dekker, 2000b), studies on maturation have usually been limited to estimating the mean total length $\left(L_{\mathrm{T}}\right)$ and age at metamorphosis (Vøllestad \& Jonsson, 1988; Vøllestad, 1992; Poole \& Reynolds, 1996; Svedäng et al., 1996). The few attempts to compute maturation rates as a function of $L_{\mathrm{T}}$ were carried out in different ways, either by empirical estimation of the parameters so as to match model predictions with field observations (Sparre, 1979), or by rigorously fitting parameterized demographic models to available data (De Leo \& Gatto, 1995), or by using length-structured cohort analysis models on catch data (Dekker, 2000c). In the present work, a simple maturation model, explicitly accounting for sexual dimorphism and temporal variation of maturation rates, was used to test the influence of different environmental conditions on maturation parameters.

According to both field observations and previous demographic studies (Vøllestad, 1992; De Leo \& Gatto, 1995), the maturation rate (here intended as a finite rate, i.e. the probability that a yellow European eel becomes silver within a given time step, for instance a month or a year) was assumed to be an increasing and saturating function of $L_{\mathrm{T}}$ :

$$
\gamma\left(L_{\mathrm{T}}\right)=\gamma_{\max }\left[1+\mathrm{e}^{\left(\lambda-L_{\mathrm{T}}\right) \eta^{-1}}\right]^{-1}
$$

where $\gamma_{\max }$ is the asymptotic maturation rate, $\lambda$ is a semisaturation constant and $\eta$ is a shape parameter which is inversely proportional to the slope of the curve at $L_{\mathrm{T}}=\lambda$.

Equation 1 was applied to three data sets. The first was gathered between 1997 and 2003 in the brackish waters of the Vaccarès and Impériaux (V\&I) lagoons (Rhône River delta, southern France), where both yellow and silver European eels are commercially exploited. A second data set was collected between 1989 and 2002 in the adjacent Fumemorte (FM) drainage canal, a freshwater body where fishing is forbidden. The third was collected between 1974 and 1976 in the Valli di Comacchio (VC) lagoons (Po River delta, northern Italy), another brackish environment, where only silver European eels are fished. This last data set was originally analysed by Gatto et al. (1982) and then used by De Leo \& Gatto $(1995,1996)$ to develop a demographic model for the VC eel population. Table I provides a concise overview of the three sites and the corresponding data. In Camargue (V\&I and FM), yellow and silver European eels were caught with the same fishing gear during the same sampling 
TABLE I. Main features of the three study sites and corresponding data sets

\begin{tabular}{lclc}
\hline & Vaccarès-Impériaux & Fumemorte & Valli di Comacchio \\
\hline Latitude & $43^{\circ} 30^{\prime} \mathrm{N}$ & $43^{\circ} 30^{\prime} \mathrm{N}$ & $44^{\circ} 40^{\prime} \mathrm{N}$ \\
Longitude & $4^{\circ} 30^{\prime} \mathrm{E}$ & $4^{\circ} 30^{\prime} \mathrm{E}$ & $12^{\circ} 10^{\prime} \mathrm{E}$ \\
Salinity & $3 \cdot 8-38 \cdot 0$ & $0 \cdot 9$ & $23-37$ \\
Winter temperature $\left({ }^{\circ} \mathrm{C}\right)$ & 7 & 7 & 2 \\
Summer temperature $\left({ }^{\circ} \mathrm{C}\right)$ & $21-22$ & $21-22$ & 24 \\
Sampling period & $1997-2003$ & $1989-2002$ & $1974-1976$ \\
Sample size & & & \\
$\quad$ Males (yellow/silver) & $622 / 275$ & $19 / 37$ & $8 / 159^{*}$ \\
$\quad$ Females (yellow/silver) & $354 / 62$ & $126 / 96$ & $29 / 334^{*}$ \\
$L_{\mathrm{T}}(\mathrm{mm})$ & $74-722$ & $67-825$ & $123-709$ \\
\hline
\end{tabular}

Salinity and temperature data from Dallocchio et al. (1998), Acou et al. (2003) and Poizat et al. (2004). *Yellow and silver counts in Comacchio are not directly comparable as the fishing procedures used were different.

$L_{\mathrm{T}}$, total length.

sessions. Hence, the observed proportion of silver European eels in each $L_{\mathrm{T}}$ class of the sample was assumed to accurately reflect the distribution of silver European eels in the population. At VC, silver European eels were sampled from the professional catch of 1975-1976 at the so-called Lavorieri (screens located at the sluice gates of the canals connecting the lagoons to the sea), whilst yellow European eels were caught by a shallow water trawl at the beginning of autumn 1976. Yellow abundances in the VC sample were rescaled by a proportionality coefficient [estimated by Gatto et al. (1982)] to account for the differences in fishing effort and selectivity of the fishing gear between the two samples. Since silvering takes place in autumn, only data collected from September to November were used for the estimation of maturation rates.

For all populations, maturation rates were calculated on an annual basis. For the V\&I population, the number of data was sufficient to calculate also monthly maturation rates. On an annual basis, the maturation rate was calculated simply as the proportion $\pi_{\mathrm{S}}$ of silver European eels in every $L_{\mathrm{T}}$ class of the autumn population structure. In fact, mature fish abandon the study sites shortly after maturation (usually in winter), so silver European eels observed in autumn samples must have silvered during the current season and the silvering probability coincides with the fraction of silver European eels within the $L_{\mathrm{T}}$ class. To calculate monthly maturation rates, the effect of progressive maturation was accounted for as follows. Let $N_{\mathrm{Y}}(t)$ and $N_{\mathrm{S}}(t)$ be the number of yellow and silver European eels, respectively, in a given population and in a given month $t$, and let $\gamma$ and $\sigma$ be the maturation and survival rates. The number of silver eels at time $t+1$ was derived as the number of silver already present plus that of those matured in the meanwhile, multiplied by the survival rate:

$$
N_{\mathrm{S}}(t+1)=\sigma\left[N_{\mathrm{S}}(t)+\gamma N_{\mathrm{Y}}(t)\right]
$$

Dividing both members by the total number of European eels at time $t+1$, considering that $N(t+1)=\sigma N(t)$, and indicating with $\pi_{\mathrm{Y}}(t)$ and $\pi_{\mathrm{S}}(t)$ the 
proportions of yellow and silver European eels at time $t$, respectively, equation (2) was rewritten as:

$$
\pi_{\mathrm{S}}(t+1)=\pi_{\mathrm{S}}(t)+\gamma \pi_{\mathrm{Y}}(t)
$$

Noting that $\pi_{\mathrm{S}}+\pi_{\mathrm{Y}}=1$ by definition, and solving equation 3 with respect to $\gamma$, the maturation rate was finally calculated as:

$$
\gamma=\left[\pi_{\mathrm{S}}(t+1)-\pi_{\mathrm{S}}(t)\right]\left[1-\pi_{\mathrm{S}}(t)\right]^{-1}
$$

The equations above are valid only if $\gamma$ and $\sigma$ are constant in time and equal for yellow and silver European eels. This assumption is likely to be verified with good approximation if the population is divided by sex and in sufficiently narrow $L_{\mathrm{T}}$ classes $(30 \mathrm{~mm}$ classes were used for males and $50 \mathrm{~mm}$ ones for females, whose body size spans over a wider range). Optimal values for maturation curve parameters were found by minimizing the mean squared error between the maturation rates predicted by the model (equation 1) and those calculated from catch data with equation 4. Maturation parameters $\gamma_{\max }, \eta$ and $\lambda$ were estimated independently for males and females at the three sites. Uncertainty of parameter estimates and relevant statistics were assessed with bootstrapping (Efron, 1979). Bootstrapping was stratified in $L_{\mathrm{T}}$ and sex classes to follow the original sampling procedure (Efron \& Tibshirani, 1986).

The results of calibrating the maturation models are reported in Table II. Maturation rates calculated from the original data sets and the corresponding fitting curves are shown in Fig. 1. Monthly maturation curves for the V\&I populations are shown in Fig. 1(a) and (b), whilst in Fig. 1(c), (d) and (e) annual maturation curves of the three populations are compared.

As for monthly maturation rates in V\&I, the dependency of maturation parameters upon sex and time was assessed by statistical tests on bootstrapped distributions obtained from the September and October subsets. The $\lambda$ was significantly influenced by sex (c. 550 v. $360 \mathrm{~mm}$ for females and males, respectively) and slightly less significantly by time (two-way ANOVA, d.f. $=1$, 3999, $P<0.001$ for sex, d.f. $=1,3999, P=0.001$ for time). On the contrary, $\gamma_{\max }$ changed remarkably with time (from $c .0 .65$ in September to 1 in October) but was not affected by sex (two-way ANOVA, d.f. $=1,3999, P<0.001$ for time, $P>0.05$ for sex). Finally, $\eta$ varied with both time and sex (two-way ANOVA, d.f. $=1,3999, P<0.001$ for both factors).

The effect of the environment on silvering was assessed in the same way by comparing parameter distributions of the annual maturation curves obtained for the three populations. All maturation parameters varied with both sex and site (two-way ANOVA, d.f. $=1,5999, P<0.001$ for both factors). The strong sex dimorphism of maturation paths, however, could have masked some subtler differences as regards the influence of the site. Therefore, bootstrap distributions of all parameters were compared pair-wise (two populations at a time) by means of a Wilcoxon matched pairs test. Inter-site differences were significant $(P<$ $0 \cdot 001)$ for all parameters except $\lambda$ of females and $\gamma_{\max }$ of males, which did not 


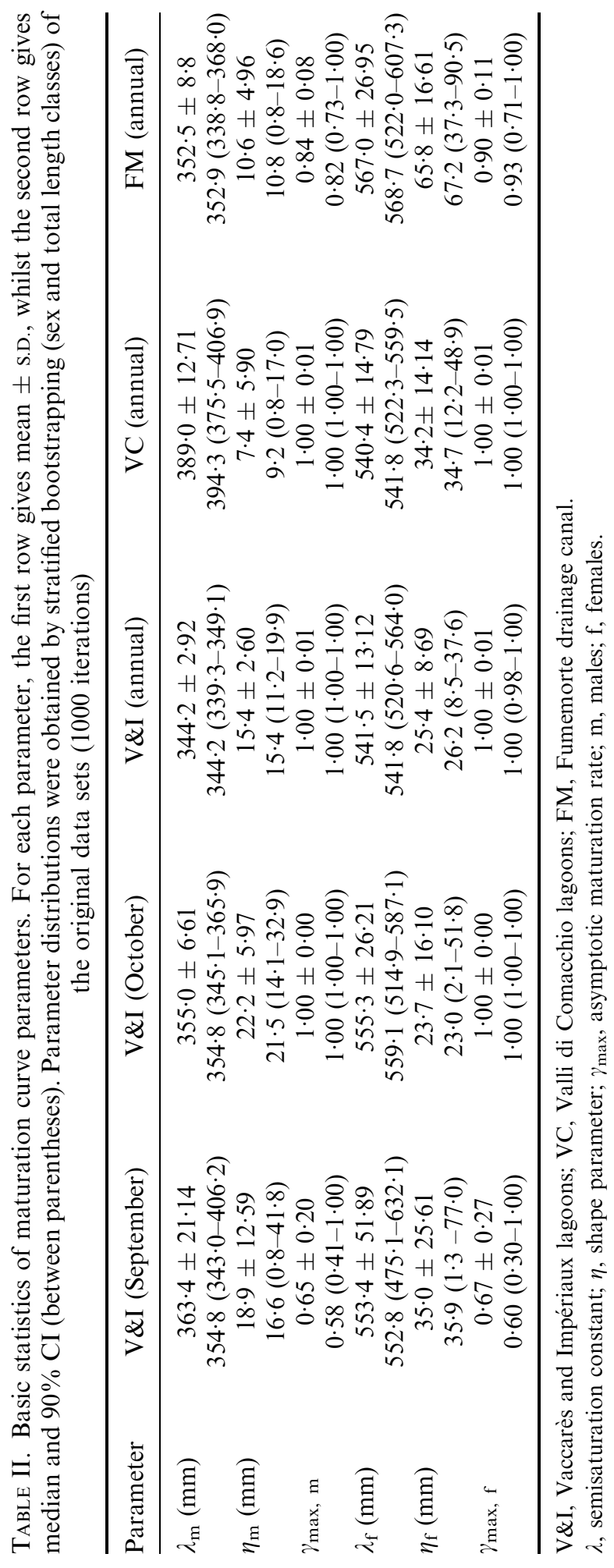



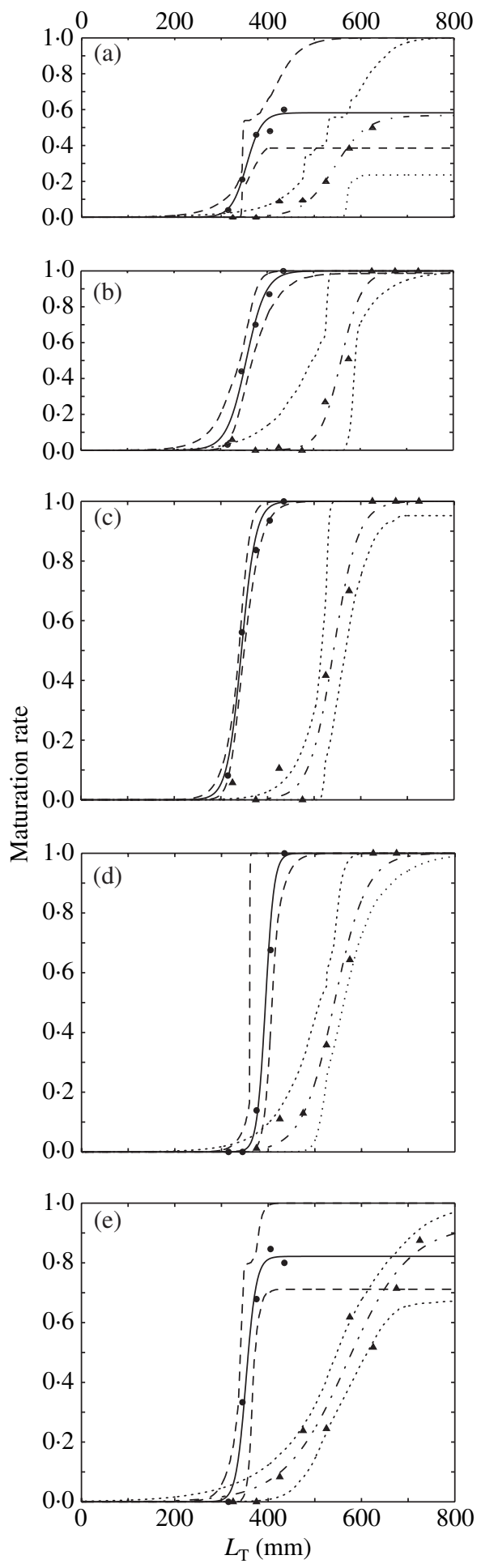
differ significantly between the two brackish-water populations (both $P>0.05$ ). Although this was only partially confirmed by statistical tests, average $L_{\mathrm{T}}$ at metamorphosis was very similar at all sites for both sexes. In all populations average $L_{\mathrm{T}}$ at sexual maturation was higher in females than in males in accordance with current knowledge (Vøllestad, 1992; De Leo \& Gatto, 1995; Svedäng et al., 1996; Dekker, 2000c; Acou et al., 2003). It is interesting to notice that in all investigated populations $\eta$ (which is inversely correlated to the slope of maturation curves) and the S.D. of $\lambda$ were higher in females than in males (Wilcoxon test, $P<0.001$; Levene's test, $P<0.001)$. This confirms the empirical observation by Vøllestad (1992) that the average $L_{\mathrm{T}}$ at sexual maturation is more variable in females than in males and corroborates the hypothesis that males undergo sexual maturation as soon as they attain the minimum body size necessary to afford migration, whilst for females there is trade-off between maximizing fecundity (by continuing growth and postponing reproduction) and minimizing the probability of dying in continental waters (Vøllestad, 1992).

The asymptotic maturation rate was equal to 1.0 for both sexes in the two brackish-water populations, whilst it was slightly lower in fresh water $(0.9$ for females and 0.8 for males), suggesting that silvering is more difficult in freshwater environments. So far, appreciable differences in maturation between fresh and brackish waters were found only for the average age at metamorphosis. In fact, growth is known to be slower in fresh water and, consequently, European eels take longer to reach the suitable size for metamorphosis (Acou et al., 2003; Melià et al., 2006b). Asymptotic maturation rates derived in the present analysis are appreciably higher than those found by Dekker (2000c) for the IJsselmeer population and by De Leo \& Gatto $(1995,1996)$ for Comacchio. A comparative analysis with Dekker's (2000c) estimates is not possible due to the different approaches used in his and this work. It is instead interesting to compare the difference between present estimates and those obtained by De Leo \& Gatto (1995) using the same data set for VC. In fact, they estimated that the asymptotic mean \pm S.D. maturation rate for females was equal to $0.34 \pm 0.09$, far below the present estimate $(1 \cdot 00 \pm 0 \cdot 01)$. This discrepancy is probably due to the different procedures used to calibrate the models. In fact, the estimate of De Leo \& Gatto (1995) is the result of the concurrent calibration of eight unknown demographic parameters and might be biased by overparameterization. In contrast, the present estimate has been obtained by calibrating only the three parameters of a single maturation curve. Although this estimate might also be affected by some biases (e.g. the fact that yellow and silver European eels counts are not directly comparable), splitting the calibration of complex demographic models into several small models focused on specific life-history events can help bypass some computational problems and obtain more reliable results.

FIG. 1. Estimated median $\pm 90 \%$ CI maturation rates for male (-, - - ) and female (---, ....) European eels at (a), (b) and (c) Vaccarès-Impériaux, (d) Valli di Comacchio and (e) Fumemorte. (a) and (b) are monthly maturation (September and October, respectively), whilst (c), (d) and (e) are annual.

$\boldsymbol{\Delta}$, maturation rates calculated from data for each $L_{\mathrm{T}}$ class rates. 


\section{References}

Acou, A., Lefebre, F., Contournet, P., Poizat, G., Panfili, J. \& Crivelli, A. J. (2003). Silvering of female eels (Anguilla anguilla) in two sub-populations of the Rhone delta. Bulletin Français de la Pêche et de la Pisciculture 368, 55-68.

Beullens, K., Eding, E. H., Gilson, P., Ollevier, F., Komen, J. \& Richter, C. J. J. (1997). Gonadal differentiation, intersexuality and sex ratios of European eel (Anguilla anguilla L.) maintained in captivity. Aquaculture 153, 135-150.

Dallocchio, F., Ghion, F., Milan, C. \& Viaroli, P. (1998). Variazioni temporali delle caratteristiche chimico-fisiche delle acque delle Valli di Comacchio. Laguna 5, 4-15.

Dekker, W. (2000a). The fractal geometry of the European eel stock. ICES Journal of Marine Science 57, 109-121.

Dekker, W. (2000b). A Procrustean assessment of the European eel stock. ICES Journal of Marine Science 57, 938-947.

Dekker, W. $(2000 c)$. Impact of yellow eel exploitation on spawner production in Lake IJsselmeer, the Netherlands. Dana 12, 17-32.

Dekker, W. (2003). Did lack of spawners cause the collapse of the European eel, Anguilla anguilla? Fisheries Management and Ecology 10, 365-376.

De Leo, G. A. \& Gatto, M. (1995). A size and age-structured model of the European eel (Anguilla anguilla L.). Canadian Journal of Fisheries and Aquatic Sciences 52, 1351-1367.

De Leo, G. A. \& Gatto, M. (1996). Trends in vital rates of the European eel: evidence for density dependence? Ecological Applications 6, 1281-1294.

Durif, C., Dufour, S. \& Elie, P. (2005). The silvering process of Anguilla anguilla: a new classification from the yellow resident to the silver migrating stage. Journal of Fish Biology 66, 1025-1043. doi: 10.1111/j.1095-8649.2005.00662.x

Efron, B. (1979). Bootstrap methods: another look at the jackknife. Annals of Statistics 7, 1-26.

Efron, B. \& Tibshirani, R. (1986). Bootstrap methods for standard errors, confidence intervals and other measures of statistical accuracy. Statistical Science 1, 54-77.

Gatto, M., Laniado, E. \& Rossi, R. (1982). The management of eels in the Valli di Comacchio lagoon. In Proceedings of the International Symposium on Coastal Lagoons, SCOR/IABO/UNESCO, Bordeaux, France, 8-14 September 1981. Oceanologica Acta 5, 303-307.

Krueger, W. H. \& Oliveira, K. (1999). Evidence for environmental sex determination in the American eel, Anguilla rostrata. Environmental Biology of Fishes 55, 381-389.

Lambert, P. (1994). Synthèse des concepts de modélisation du phénomène de migration des civelles d'Anguilla anguilla (L. 1758) en estuaire. Bulletin Français de la Pêche et de la Pisciculture 335, 99-110.

Melià, P., Bevacqua, D., Crivelli, A. J., De Leo, G. A., Panfili, J. \& Gatto, M. (2006a). Age and growth of the European eel Anguilla anguilla in the Camargue lagoons. Journal of Fish Biology 68, 876-890. doi: 10.1111/j.1095-8649.2006.00975.x

Melià, P., Bevacqua, D., Crivelli, A. J., Panfili, J., De Leo, G. A. \& Gatto, M. (2006b). Sex differentiation of the European eel in brackish and freshwater environments: a comparative analysis. Journal of Fish Biology 69, 1228-1235. doi: 10.1111/j.10958649.2006.01170.x

Moriarty, C. \& Dekker, W. (1997). Management of the European eel. Fisheries Bulletin Fisheries Bulletin (Dublin) 15, 110 pp.

Poizat, G., Rosecchi, E., Chauvelon, P., Contournet, P. \& Crivelli, A. J. (2004). Longterm fish and macro-crustacean community variation in a Mediterranean lagoon. Estuarine Coastal and Shelf Science 59, 615-624.

Poole, W. R. \& Reynolds, J. D. (1996). Growth rate and age at migration of Anguilla anguilla. Journal of Fish Biology 48, 633-642.

Sparre, P. (1979). Some necessary adjustments for using the common methods in eel assessment. In Eel research and management (Thurow, F., ed.). Rapports et ProcèsVerbaux des Réunions du Conseil International pour l'Exploitation de la Mer 174, 41-44. 
Svedäng, H. \& Wickström, H. (1997). Low fat contents in female silver eels: indications of insufficient energetic stores for migration and gonadal development. Journal of Fish Biology 50, 475-486.

Svedäng, H., Neuman, E. \& Wickström, H. (1996). Maturation patterns in female European eel: age and size at the silver eel stage. Journal of Fish Biology 48, 342-351.

Vøllestad, L. A. (1992). The geographic variation in age and length at metamorphosis of maturing European eel: environmental effects and phenotypic plasticity. Journal of Animal Ecology 61, 41-48.

Vøllestad, L. A. \& Jonsson, B. (1988). A 13-year study of the population dynamics of the European eel Anguilla anguilla in a Norwegian river: evidence for densitydependent mortality, and development of a model for predicting yield. Journal of Animal Ecology 57, 983-997. 